\title{
Analysis of Trends and Patterns of Annual Rainfall in Australian Cities
}

\author{
Bright Emmanuel Owusu and Nittaya McNeil
}

\begin{abstract}
The increasing concern and fear about climate change have intensified the need for precise figures about deviations in statistical characteristics of rainfall events in both temporal and spatial scales. As a result of this goal, sixty-eight years daily rainfall observations acquired from Australian Bureau of meteorology during 1950-20017, are used to determine trends and patterns.

Statistical methods comprising of parametric and non-parametric methods are used to determine annual rainfall trends in Australia. The parametric method involves linear regression analysis while the nonparametric method is the Mann Kendall test.

Rising rainfall trends were observed in Darwin and Port Hedland during 1950-2017. These increasing trends were not significant. Conversely, decreasing annual rainfall trends were observed in the remaining cities (Cairns, Alice, Perth, Newcastle, Ainslie and Hobart). The decreasing trends were observed to be significant in Hobart city.

Analysis of the monthly patterns revealed four main rainfall trends in Australia during 1950-2017.
\end{abstract}

Keywords - Australia cities, rainfall, statistical methods, trends.

\section{INTRODUCTION}

Some cities around the globe have for the past few decades experienced extreme events such as hurricanes, floods, droughts and other climate-related disasters, causing human casualties and heavy damages on properties and infrastructure. Assessment reports from [1] indicated that there is the likelihood that the incidence of heavy rainfall or the proportion of overall rainfall from heavy falls will increase in the 21 st century over many areas of the globe. The high proportion of heavy rainfall is particularly the case in the high latitudes and tropical regions. Due to changes in rainfall, resulting in varying characteristics in wet spells, climatological features have become unpredictable especially in Australia where there is high climate variability. A study by [2] revealed that, for the past few decades, the global hydrological cycle has been experiencing significant fluctuations, which comprise rainfall amount, frequency and duration. It is assumed that global

Bright Emmanuel Owusu, Department of Mathematics and Computer Science, Faculty of Science and Technology, Prince of Songkla University, Muang Pattani, 94000. Thailand.

Department of Mathematics, Presbyterian University College Ghana.

Nittaya McNeil, Department of Mathematics and Computer Science, Faculty of Science and Technology, Prince of Songkla University, Muang Pattani, 9400. Thailand.

Centre of Excellence in Mathematics, Commission on Higher Education (CHE), Ministry of Education, Ratchathewi, Bangkok, 10400 Thailand. warming will lead to a more dynamic atmosphere, which potentially leads to more frequent high-intensity rainfall events in many regions of the globe even in regions where rainfall is reducing. Rainfall processes in cities are likely to be a complicated issue due to several factors involved. One of them is urbanisation in which surface modification of the natural surface is spatially replaced with human-made or artificial impervious materials, changing or disturbing surface energy balance and the atmosphere over the area [3].

Studies such as [3]-[4] revealed that increasing population resulting in urbanisation had modified land surface processes through the formation of 'urban heat island'. The modification of the land surface influences their local to global scale climate, as variations in land use and land cover continually modify energy and moisture fields as well as circulation patterns. Moreover, a significant amount of anthropogenic heat is radiated from relatively large fuel usage. Air pollutants in the area can also play a role in increasing the number of cloud condensation nuclei, with a complex series of feedbacks to cloud formation and rainfall [5].

A study by [6] revealed that increasing surface temperature enhances clouds formation and rainfall anomalies. Surface warming has a direct effect on rainfall. Increasing heating leads to greater evaporation resulting in an efficient drying of surfaces and increasing the duration and the intensity of drought. The water holding ability of air increases by about $7 \%$ per $1{ }^{\circ} \mathrm{C}$ warming, which leads to increased water vapour in the atmosphere, which affects storm development. Also, storms supplied with increased moisture, yield more intense rainfall events [7]. Analysis of temperature change in Australia by [8] revealed similar increasing temperature patterns in many areas. This area includes the central, eastern, southern and southeastern parts of Australia.

Local precipitation patterns affected by urbanisation have been studied by some scholars [9]-[10]. These studies which focused on the effects of urban expansion on rainfall amount and frequency indicated that the seasonal or daily precipitation amount and frequency over cities and downstream areas were significantly larger than those in the non-urban area. It is, therefore, necessary to investigate daily rainfall variability in Australia.

This study examines and describes the trends and pattern of rainfall in Australia during 1950-2017. 


\section{II.DATA AND METHODS}

This study used 68 years (1950-2017) daily aggregated rainfall data for eight observational weather stations in cities spread over Australia. The data were obtained from Australian Bureau of Meteorology (http://www.bom.gov.au/climate/data). These eight stations in cities were selected to give a sample covering the whole Australia as evenly as possible, and they have continuous rainfall records that extend over a period of 68 years (Fig. 1). Data recorded on leap years were omitted to maintain standard year with 365 days observations, and thus each station was made up of 24,820 observations for the 68 years records. For each station, the 5-day average rainfall (mean rainfall in successive 5 days) was computed and used in this study. This choice in the statistical analysis has the following advantages; the proportion of missing data is substantially reduced, daily patterns are represented well graphically, the correlation between data in consecutive periods is substantially reduced.

The trend in an index of precipitation was calculated by using the simple linear regression and the Mann-Kendall trend tests.

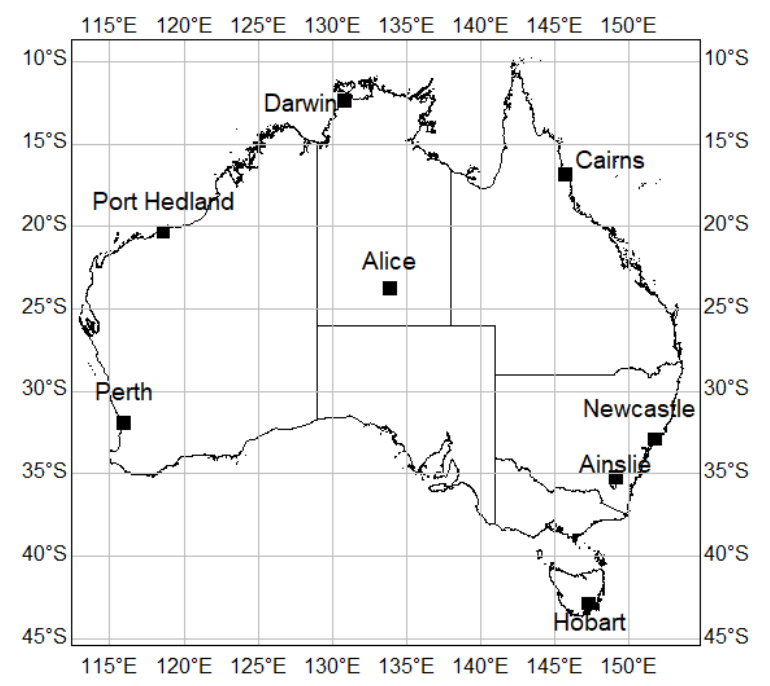

Fig. 1 The map of Australia and the locations of stations in the cities used in the study

The linear regression used in determining the trend in the annual rainfall time series is defined as

$$
y_{i}=\beta_{0}+\beta_{1} x_{i}+\varepsilon_{i}
$$

where $y_{i}$ is the value of the index at a year $i$ and $\varepsilon_{i}$ is the residual or error term with mean zero. The regression parameters $\beta_{0}$ and $\beta_{1}$ are estimated by the method of least squares. The method of least squares was used because it estimates the parameters such that their sums of squares error are minimized. The parameter and $\beta_{1}$ gives the change per decade.

The Mann-Kendall trend test was also used to determine the trend in the annual rainfall time series. The Mann-Kendall test is a non-parametric test that can be used to identify trends in a time series [11] when there is no significant serial correlation in the data. The major advantages of this method are that no assumptions about the distribution of the data are required and it is also directly applicable to climate data for a given month, season and year. The Mann-Kendall statistic, denoted by S, is defined as follows:

$$
S_{i}=\sum_{i=1}^{n-1} \sum_{j=i+1}^{n} \operatorname{sgn}\left(x_{j}-x_{i}\right)
$$

where the $x_{j}$ are the sequential data values, $\mathrm{n}$ is the length of the data set, and

$$
\operatorname{sgn}\left(x_{j}-x_{i}\right)\left\{\begin{array}{cc}
1, & \text { if } x_{i}<x_{j} \\
0 & \text { if } x_{i}=x_{j} \\
-1 & \text { if } x_{i}>x_{j}
\end{array}\right.
$$

The statistic $\mathrm{S}$ is approximately normally distributed when with the mean and the variance as follows respectively:

$$
\begin{aligned}
& E(S), \quad(4) \\
& V(S)=\frac{n(n-1)(2 n+5) \sum_{i=1}^{n} t_{i} i(i-1)(2 i-5)}{18},
\end{aligned}
$$

where $t_{i}$ is the number of ties of extent $\mathrm{i}$.

The standardised test statistic $(\mathrm{Z})$ of the Mann-Kendall test and the corresponding $\mathrm{p}$-value (p) for the one-tailed test are respectively given by

$$
\begin{gathered}
Z= \begin{cases}\frac{s-1}{\sqrt{\operatorname{var}(s)}} 1, & \text { if } s>0 \\
0 \quad \text { if } s=0 & s+1 \\
\frac{s+1}{\sqrt{\operatorname{var}(s)}} & \text { if } s<0\end{cases} \\
p=0.5-\phi(|z|),
\end{gathered}
$$

where $\phi(|z|)$ is the standard normal distribution. When the p-value is very small random sampling has little effect on the trend. A positive $\mathrm{Z}$ value depicts an increasing trend while negative $Z$ values indicate a decreasing trend. Trend testing is done at a certain level of significant $(\alpha)$. A significant level of $5 \%$ was used in this study, and this implies that the assumption that the slope of the trend line $\left(\beta_{1}=0\right)$ will be rejected if

$$
(|z|)>z_{\alpha / 2} \text {. }
$$

\section{RESULTS AND DISCUSSION}

\section{A. Analysis of the 5-day average rainfall}

The 5-day average rainfall was initially explored using descriptive statistics, and the result is given in Table I. Cairns had the highest rainfall mean of $5.5 \mathrm{~mm}$ followed by Darwin and Newcastle with rainfall means of 4.80 and $3.07 \mathrm{~mm}$ 
respectively. The least rainfall mean of $0.78 \mathrm{~mm}$ was recorded in Alice. Interestingly, the highest rainfall coefficient of variations $(\mathrm{CV})$ of 423 and 359 were recorded in the areas with the least rainfall means (Alice and Port Hedland respectively).

Fig. 2 shows the graph of the 5-day rainfall averages monthwise. The comparison of the 5-day average rainfall among the cities revealed substantial spatial variability in the study area. Among the wettest cities, Cairns and Darwin show similar patterns, with wet months from December to March. Port Hedland and Alice seem to have similar patterns with a tremendous amount of rainfall between January and April. A significant amount of rainfall occurred between (the wettest months) May and August in Perth. Conversely, Newcastle, Ainslie and Hobart seem to have similar patterns. These areas experience uniform rainfall throughout the year. Thus, four main rainfall patterns are revealed during 1950-2017 in Australia.

There were no apparent patterns of the average annual rainfall station-wise (Fig. 3). However, annual rainfall was not uniformly distributed in the study area. Annual rainfall varies from 0.32 to $5.50 \mathrm{~mm}$ in the study area. The highest annual average of $5.50 \mathrm{~mm}$ occurred in Cairns, and the least of 0.33 mm was observed in Alice during 1950-2017.

\section{B. Analysis of the Annual Rainfall Trends}

Analysis of the trends of the mean annual rainfall over Darwin and Port Hedland and by both the linear regression method and the Mann-Kendall test showed long-term increasing trends. While the linear regression method revealed a significant increasing trend $(\mathrm{p}<0.05)$ in Port Hedland during 1950-2017, the Mann-Kendall test revealed non-significant increasing trend during the same period (Fig. 4, Table II). The increasing annual rainfall trends in these cities is consistent with the available literature. For instance, trend analysis of rainfall by [12]-[13] suggested that the increasing rainfall trends may be due to enhanced aerosol resulting from anthropogenic activities. The aerosol is particular from Asia and moves around northwestern Australia.

Daily means (from 5-day aggregates): 1950-2017

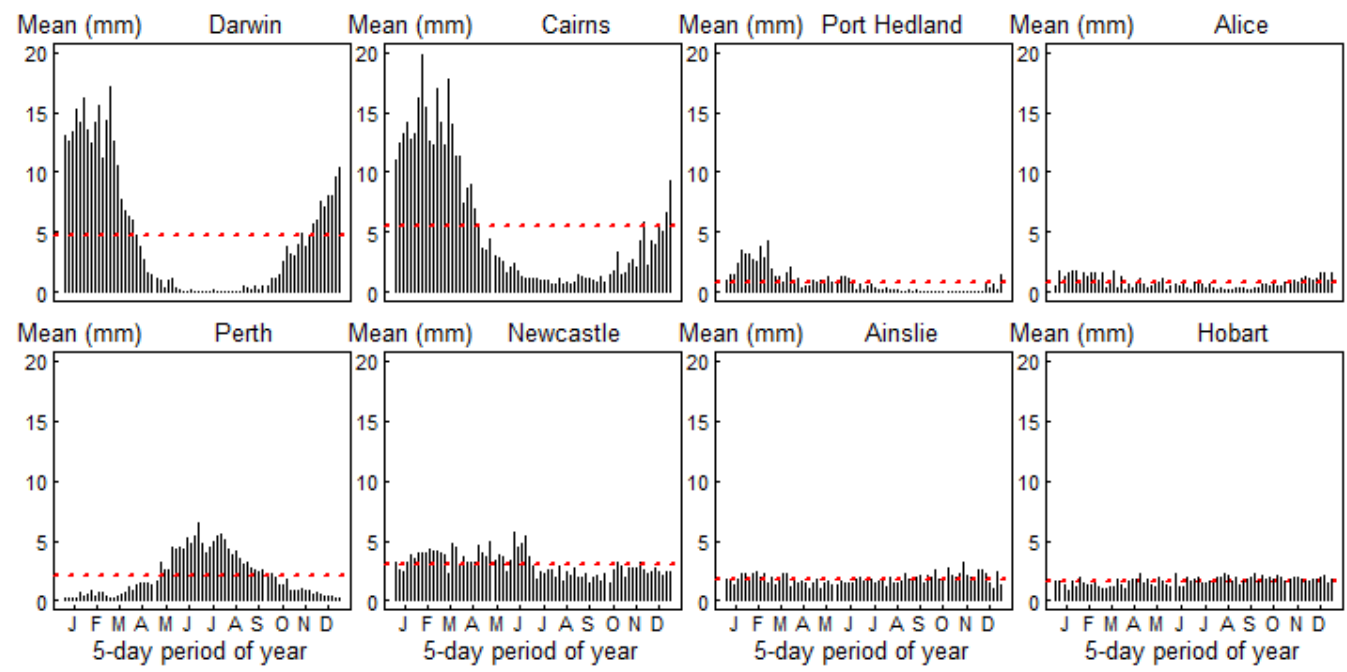

Fig. 2. The graph of the monthly distribution of rainfall in Australia during 1950-2017. The dotted lines show the overall mean 
Annual daily means (from 5-day aggregates): 1950-2017
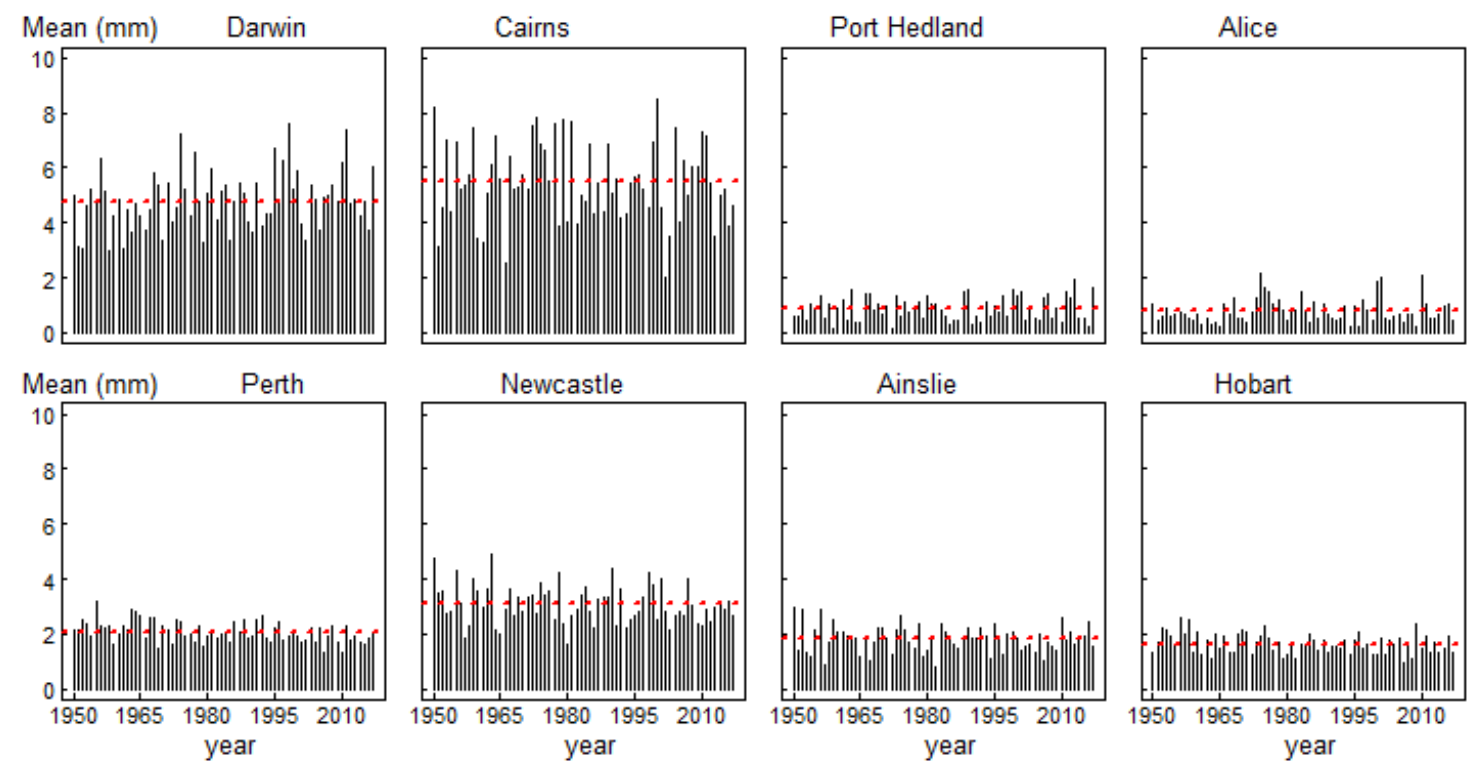

Fig. 3. The annual daily rainfall in Australias during 1950-2017. The dotted lines show the overall mean and the vertical bar show the observed.

TABLE I

SUMMARY STATISTICS OF THE 5-DAY RAINFALL FOR THE DATASET (19502017), FOR THE NINE SELECTED STATIONS

\begin{tabular}{|l|c|c|c|c|c|c|}
\hline $\begin{array}{l}\text { Station } \\
\text { Name }\end{array}$ & $\begin{array}{l}\text { Lat } \\
\left({ }^{\circ} \mathrm{C}\right)\end{array}$ & $\begin{array}{l}\text { Lon } \\
\left({ }^{\circ} \mathrm{C}\right)\end{array}$ & $\begin{array}{l}\text { Elev } \\
(\mathrm{m})\end{array}$ & $\begin{array}{l}\text { Mean } \\
(\mathrm{mm})\end{array}$ & $\begin{array}{l}\text { Median } \\
(\mathrm{mm} / \mathrm{d})\end{array}$ & $\begin{array}{l}\mathrm{CV} \\
(\%)\end{array}$ \\
\hline Darwin & 12.42 & 130.89 & 30 & 4.81 & 0.24 & 199 \\
\hline Cairns & 16.87 & 145.75 & 58 & 5.50 & 5.24 & 219 \\
\hline $\begin{array}{l}\text { Port } \\
\text { Hedland }\end{array}$ & 20.37 & 118.63 & 10 & 0.86 & 0.00 & 423 \\
\hline Alice & 23.8 & 133.89 & 395 & 0.78 & 0.00 & 359 \\
\hline Perth & 31.93 & 115.98 & 360 & 2.07 & 0.36 & 163 \\
\hline Newcastle & 32.92 & 151.80 & 20 & 3.07 & 1.02 & 171 \\
\hline Ainslie & 35.26 & 149.14 & 240 & 1.81 & 0.52 & 164 \\
\hline Hobart & 42.89 & 147.33 & 15 & 1.64 & 0.72 & 161 \\
\hline
\end{tabular}

Note: Lat (latitude), lon (longitude), Elev (elevation)

The mean annual rainfall over Ainslie and Newcastle indicated a long-term significant negative trend that is significant at the 0.05 significance level (Fig. 4, Table II) during 1950-2017. The observed decreasing annual rainfall trends in Ainslie, Hobart and Newcastle are consistent with a study by [14]. They revealed distinctive shortfalls in rainfall in southeastern Australia. This rainfall deficit was evident in prewinter and early winter rainfall. They attributed the decreasing rainfall trends to partly associated with variations in largescale atmospheric circulation [14]-[15] and may also be due to variations in anthropogenic greenhouse gases [16] floating in the urban air. In addition, non-significant declining annual rainfall trend during the whole study period (Fig. 4, Table II) was also observed in Perth, Cairns and Hobart.

\section{CONCLUSION}

An essential part of this study is the variability of trends and patterns in the annual rainfall that has been identified at the selected cities of Australia.

TABLE II

THE Results of THE LineAR REgRESSION, MANN-KENDALL TEST IN DETERMINING TRENDS

\begin{tabular}{|c|c|c|c|c|}
\hline & \multicolumn{2}{|c|}{ Linear regression } & \multicolumn{2}{l|}{ Mann-Kendall test } \\
\hline Station Name & $\beta_{1}$ & $p$-value & $\mathrm{z}$ & $p$-value \\
\hline Darwin & 0.012 & 0.02 & 1.79 & 0.07 \\
\hline Cairns & -0.0001 & 0.88 & -0.30 & 0.77 \\
\hline Port Hedland & 0.003 & 0.34 & 0.69 & 0.49 \\
\hline Alice & -0.003 & 0.28 & -1.01 & 0.31 \\
\hline Perth & -0.007 & 0.45 & -0.79 & 0.43 \\
\hline Newcastle & -0.01 & 0.02 & -2.15 & 0.03 \\
\hline Ainslie & -0.001 & 0.003 & -2.95 & 0.003 \\
\hline Hobart & -0.007 & 0.10 & -1.52 & 0.13 \\
\hline
\end{tabular}

The analysis discovered increasing annual rainfall trends at Darwin and Port Hedland. Conversely, there is no cause for alarm since these increasing trends, were not statistically significant. Significant reducing trends were also identified during 1950-2017 in Newcastle and Ainslie by the statistical methods. Further studies could examine recent changes in rainfall for the last 30 years to examine if the has been climate change regarding rainfall during the recent period. 
Annual daily means (from 5-day aggregates): 1950-2017
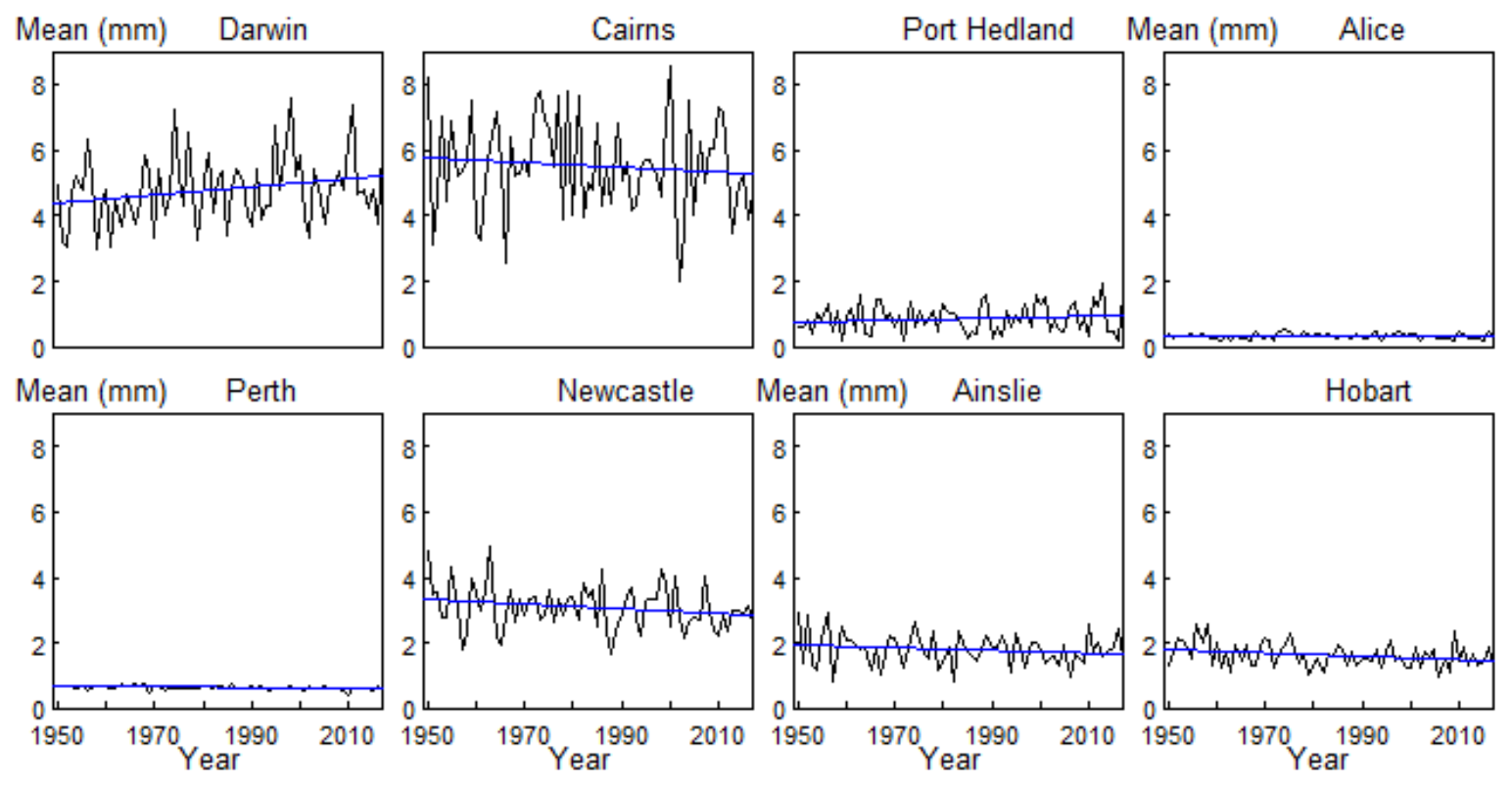

Fig. 4 Trends in the annual rainfall time series of the station. The curves show the observed annual rainfall, and the straight line denotes the trend

\section{ACKNOWLEDGMENT}

We are grateful to the Higher Education Research Promotion and Thailand's Education Hub for Southern Region of ASEAN Countries and Presbyterian University College Ghana for providing support to the first Author.

\section{REFERENCES}

[1] IPCC, "Managing the Risks of Extreme Events and Disasters to Advance Climate Change Adaptation", Special Report of the Intergovernmental Panel on Climate Change Extreme, pp. 1-594, 2012.

[2] K. E. Trenberth, and D. P. Stepaniak, "Covariability of components of poleward atmospheric energy transports on seasonal and interannual timescales," J. Clim., Vol. 16, no. 22, pp. 3691-705, Nov. 2003.

[3] T. R. Oke, "The urban energy balance," Prog. Phys. Geogr., Vol. 12, no. 4, pp. 471-508, Dec. 1988.

[4] J. M. Shepherd, "A review of current investigations of urban-induced rainfall and recommendations for the future," Earth Interact., Vol. 9, no. 12, pp. 1-27, Jul. 2005.

[5] W. Shem, and J. M Shepherd, "On the impact of urbanization on summertime thunderstorms in Atlanta: Two numerical model case studies," Atmos. Res., Vol. 92, pp. 172-189, 2009.

[6] L. M. Hand, and J. M. Shepherd, "An investigation of warm-season spatial rainfall variability in Oklahoma City: Possible linkages to urbanization and prevailing wind," Appl. Meteorol. Climatol., pp. 251269, 2009.

[7] K. E. Trenberth, "Changes in precipitation with climate change," Clim. Res., Vol. 31, no. 47, pp. 123-38, Mar. 2011.

[8] W. Wanishsakpong, N. McNeil, and K. A. Notodiputro, "Trend and pattern classification of surface air temperature change in the Arctic region," Atmos. Sci. Lett., Vol. 17, no. 7, pp. 378-83, Jul. 2016.

[9] S. A. Changnon Jr, "Recent studies of urban effects on precipitation in the United States," Bull. Am. Meteorol. Soc., pp. 411-211, Jun 1969.

[10] F. A. Huff, and S. A. Changnon Jr, "Climatological assessment of urban effects on precipitation at St. Louis," J. Appl. Meteorol., Vol. 11, no. 5, pp. 823-42, Aug. 1972.

[11] H. B. Mann, "Nonparametric tests against trend. Econometrica," Econometrica., pp. 245-59, Jul. 1945.
[12] R. Wardle, I. Smith, "Modeled response of the Australian monsoon to changes in land surface temperatures," Geophys. Res. Lett., Vol. 31, no. 16, Aug. 2004.

[13] L. D. Rotstayn et al., "Have Australian rainfall and cloudiness increased due to the remote effects of Asian anthropogenic aerosols?," J. Geophys., Res., 112(D9), May 2007.

[14] B. Timbal, and R. Fawcett, "A historical perspective on southeastern Australian rainfall since 1865 using the instrumental record," J. Clim., Vol. 26, no. 4, pp. 1112-1129, Feb. 2013.

[15] N. Nicholls, "Detecting and attributing Australian climate change: a review," Aust. Meteorol. Meg., Vol. 55, no. 3, pp. 199-211, Sep. 2006.

[16] T. L. Delworth, and F. Zeng, "Regional rainfall decline in Australia attributed to anthropogenic greenhouse gases and ozone levels," Nat. Geosci., Vol. 7, no. 8, pp. 583, Aug. 2014. 